\title{
New archaeorthopteran insects from the Carboniferous of Poland: Insights into tangled taxonomy
}

Tomáš Dvořák, Martina Pecharová, Wiesław Krzemiński, and Jakub Prokop Acta Palaeontologica Polonica 64 (4), 2019: 787-796 doi:https://doi.org/10.4202/app.00614.2019

Archaeorthoptera is a high rank insect taxon comprising Orthoptera as well as the extinct orders Titanoptera and Caloneurodea, and several other late Paleozoic groups formerly assigned to polyphyletic Protorthoptera. Synapomorphies defining Archaeorthoptera and some fossil subordinate taxa are exclusively based on wing venation. This study presents a detailed description of two new archaeorthopteran genera and three new species from the Pennsylvanian of the Upper Silesian Coal Basin in Poland. These new taxa provide new insights into the wing venation disparity of this remarkable and insufficiently studied insect group. Omaliella polonica sp. nov. is based on a well preserved forewing, including the wing base, which allows a thorough discussion and comparison with other archaeorthopterans. Surprisingly, it is the first complete wing for this group of related genera (Omaliella, Omalia, Coselia and Paleomastax). Owadpteron dareki gen. et sp. nov. has an unusual arrangement of cubital veins. The marked resemblance of the venation of Owadpteron to that of some members of the gerarid line, such as Nacekomia, supports its placement within the family Geraridae (stemgroup Orthoptera). Finally, the venation of Parapalaeomastax dariuszi gen. et sp. nov. strikingly resembles that of the genus Palaeomastax, differing only in the distally branched media. Discovery of these three new archaeorthopterans from the Upper Silesian Coal Basin fits well with that of closely related taxa known from other deposits in Euramerica, such as Mazon Creek Lagerstätte, Avion in Pas-de-Calais Basin and others. Furthermore, a new re-examination of the earliest archaeorthopteran from the Upper Silesian Coal Basin confirms doubtful assignment of this fragmentary fossil to Archaeorthoptera or even to Pterygota.

Key words: Insecta, Archaeorthoptera, Polyneoptera, wing venation, Pennsylvanian, Poland, Upper Silesia.

Tomáš Dvořák [algalesie@seznam.cz], Martina Pecharová [pecharom@natur.cuni.cz ] and Jakub Prokop [jprokop@ natur.cuni.cz] Department of Zoology, Faculty of Science, Charles University, Viničná 7, CZ-128 00, Praha 2, Czech Republic. Wiesław Krzemiński [wieslawk4@gmail.com] Institute of Systematics and Evolution of Animals, Polish Academy of Sciences, ul. Sławkowska 17, 31-016, Kraków, Poland. 
This is an open-access article distributed under the terms of the Creative Commons

Attribution License (for details please see creativecommons.org), which permits unrestricted use, distribution, and reproduction in any medium, provided the original author and source are credited.

Forill text $(734.0 \mathrm{kB})$ 